\title{
LAS TEORÍAS DE LA DEPENDENCIA Y LA CUESTIÓN DEL ESTADO EN AMERICA LATINA: REFLEXIONES CRÍTICAS (Y AUTOCRÍTICAS) EN LA BISAGRA DE LOS AÑOS SETENTA Y OCHENTA
}

\author{
Andrés Tzeiman ${ }^{1}$
}

\section{Resumen/Abstract}

El presente artículo pretende llevar a cabo una revisión de un conjunto de textos escritos en un momento muy particular y fugaz en el marxismo latinoamericano. Nos referimos a un cúmulo de producciones que se llevaron a cabo en la bisagra de los años setenta y ochenta. Hablamos de un contexto de derrota para los sectores subalternos, luego del proceso de avance popular ocurrido en la región durante los años sesenta y la primera mitad de los setenta. En ese cruce de décadas, tras la irradiación de los estudios sobre la dependencia en América Latina, las preocupaciones de tales enfoques se intersectan con una indagación en torno del fenómeno estatal. En estas páginas realizaremos una revisión de dicho momento de reflexión teórica, a partir del análisis de algunos trabajos de cuatro figuras del marxismo latinoamericano: Norbert Lechner (alemán, naturalizado chileno), Agustín Cueva (ecuatoriano), René Zavaleta (boliviano) y Marcos Kaplan (argentino).

Palabras Clave: Estado, dependencia, marxismo, América Latina.

THEORIES OF DEPENDENCE AND THE QUESTION OF THE STATE IN LATIN AMERICA: CRITICAL (AND AUTOCRITICAL) REFLECTIONS IN THE HINGE OF THE SEVENTIES AND

This article aims to carry out a review of a set of texts written at a very particular and fleeting moment in Latin American Marxism. We refer to the number of productions that took place at the frontier of the seventies and eighties. We are meaning a context of defeat for the subaltern sectors, after the process of popular advance in the region occurred during the sixties and the first half of the seventies. In this hinge of decades, after the irradiation of studies on dependency in Latin America, the concerns of such approaches intersect with an inquiry about the state phenomenon and its Latin American specificity. In these pages, we will review this moment of theoretical reflection, by the analysis of some work of four figures of Latin American Marxism: Norbert Lechner (German, Chilean naturalized), Agustín Cueva (Ecuadorian), René Zavaleta (Bolivian) and Marcos Kaplan (Argentinian).

Keywords: State, dependency, Marxism, Latin America.

\footnotetext{
${ }^{1}$ Universidad de Buenos Aires, Argentina. E-mail: andrestzeiman@hotmail.com
} 


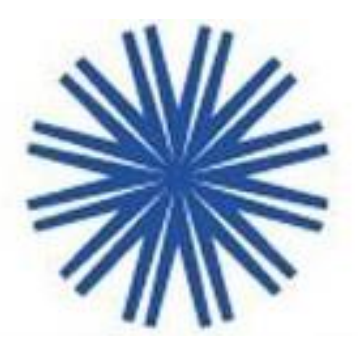

Introducción: pensar el Estado en tiempos de derrota El segundo quinquenio de los años setenta mostraba un panorama bastante desolador en América Latina. Especialmente en lo relativo a la situación política en el Cono Sur. Realizando un paneo por los distintos países que integran a ésta última subregión, se podía observar sin dificultades que la instauración de dictaduras cívico-militares resultaba allí predominante.

Buscando graficar lo que sucedía en ese entonces, en un artículo titulado América Latina en el último quinquenio: 1976-1980, publicado en 1980 en la revista Araucaria (cuyo director, desde el exilio, era el dirigente comunista chileno Volodia Teitelboim), el sociólogo ecuatoriano Agustín Cueva retrataba de la siguiente forma el paisaje político que reinaba en la región en los últimos años de la década del setenta:

Un breve recuento de la situación de América Latina al comenzar la segunda mitad de la década pasada [la del setenta] sirve para recordarnos el panorama harto deprimente que caracterizaba a la región en aquel entonces. La dictadura militar del país más importante del subcontinente, el Brasil, parecía estar plenamente consolidada al cabo de doce años de ejercicio del poder y dotada de una gran capacidad de expansión en todos los órdenes. En Bolivia, país tradicionalmente turbulento, la dictadura de Banzer tenía visos de haber impuesto, <〈por fin〉>, un orden estable pro imperialista. Uruguay y Chile sufrían, por su parte, los más rigurosos efectos de los regímenes fascistas instaurados desde 1973; mientras en la Argentina el gobierno de la señora Estela Martínez de Perón se desmoronaba, dando paso a la férrea dictadura del general Videla. Sojuzgado por la tiranía de Stroessner desde 1954, el Paraguay no hacía más que corroborar el trágico cuadro del Cono Sur de América Latina. (Cueva, 1980: 7).

No hacen falta mayores precisiones para afirmar que el contexto latinoamericano resultaba, en ese entonces, demasiado sombrío. Sin embargo, en materia teórica, dicha situación concitó un profundo interés en la intelectualidad crítica de la región, ligado tanto a la necesidad de explicar el fenómeno de las dictaduras emergentes, como a reflexionar sobre la estrategia que debían adoptar los movimientos populares en los diferentes países, con el objeto de acabar con los regímenes de facto, y a su vez, reinstaurar condiciones favorables de lucha de cara a la transformación del orden social. 
Por esa razón, el fin de los setenta y comienzo de los ochenta no resultó residual en términos de producción teórica. Por el contrario, aquellos años en el marxismo latinoamericano fueron sumamente prolíficos en varios aspectos. Así, en dicho contexto de derrota, se iniciaba un proceso de reflexión por parte de numerosos intelectuales de nuestra región, quienes por esos años intentaron no solo realizar un balance político acerca del retroceso de los sectores subalternos en nuestras tierras, sino también elaborar una autocrítica sobre las lentes teóricas con las cuales las izquierdas habían interpretado el devenir de los procesos sociales durante los decenios del sesenta y buena parte del setenta. En aquel escenario intelectual de fines de los setenta y comienzos de los ochenta, de reflexión desde la derrota, sumamente prolífico en cuanto a la producción teórica, despuntan un conjunto de contribuciones que consideramos particularmente valiosas. Hablamos de referentes del marxismo latinoamericano que en ese período se abocaron a reexaminar los aportes del amplio y heterogéneo conjunto de enfoques conocido como "teorías de la dependencia”, y en función de un análisis crítico sobre ellos, trataron de señalar sus virtudes y desaciertos, colocando un énfasis especial en la cuestión del Estado y el poder político en clave latinoamericana.

En este artículo abordaremos diferentes aportes teóricos en torno a la conceptualización del Estado, y en particular, a la especificidad latinoamericana del fenómeno estatal, que se produjeron críticamente (o en algunos casos, autocríticamente) con respecto al horizonte conceptual de la dependencia y el desarrollo en América Latina (predominante en los intelectuales marxistas de las ciencias sociales latinoamericanas). Aunque, ciertamente, las contribuciones sobre las que nos concentraremos en las páginas siguientes, estuvieron un tanto dislocadas temporalmente en relación con el núcleo más fuerte de trabajos que se habían inscripto en ese locus de discusiones en los años sesenta y la primera mitad de los setenta. Nos referiremos, por tanto, a las resonancias tardías del debate sobre la dependencia y el desarrollo en América Latina. Hablamos, así, de reflexiones que marcan un desplazamiento en términos de inquietudes teóricas, signado por cierto abandono de problemáticas conceptuales y políticas tales como las clases sociales, los modos de producción y el imperialismo (tópicos predominantes en los sesenta y la primera mitad de los setenta), para inclinarse hacia un estudio más enfocado sobre las dimensiones de lo político y lo estatal.

Con el propósito de analizar la productividad teórica del desplazamiento señalado en el párrafo, en las siguientes páginas intentaremos recuperar a cuatro figuras del marxismo latinoamericano que en el cruce de los años setenta y ochenta se dedicaron a reflexionar acerca de la cuestión estatal, en su relación con el 
fenómeno de la dependencia en América Latina. A continuación, repasaremos los aportes teóricos realizados por Norbert Lechner (alemán, aunque naturalizado chileno), Agustín Cueva (ecuatoriano), René Zavaleta Mercado (boliviano) y Marcos Kaplan (argentino).

Norbert Lechner: el Estado latinoamericano ante la hegemonía externa y la heterogeneidad estructural Como señalamos en la introducción, las contribuciones teóricas acerca del fenómeno estatal que rescataremos a lo largo de las siguientes páginas fueron parte de un movimiento del universo intelectual crítico de América Latina, que se desplazó hacia un creciente interés por el estudio de la cuestión estatal. Tal es así que, como sostiene Norbert Lechner, en la segunda mitad de los años setenta hasta el comienzo de los ochenta, el Estado se convirtió en el eje aglutinador de la investigación social en América Latina (Lechner, 2006a: 349-350). En la Presentación del libro titulado Estado y política en América Latina publicado en 1981, en el que compilara artículos escritos por destacados intelectuales latinoamericanosel mencionado politólogo chileno-alemán explicaba con claridad la relevancia del estudio del fenómeno estatal en nuestra región en aquel contexto:

Las dificultades por precisar qué y cómo es el estado capitalista sui generis en la región revelan un "déficit teórico" que contrasta con la movida lucha política. Precisamente porque los conflictos en las sociedades latinoamericanas siempre involucran al estado, su insuficiente conceptualización deja de ser un asunto académico. Presumo que a las recientes crisis políticas no les es ajena una crisis del pensamiento político. (Lechner, 2000: 7; énfasis del original).

Pues bien, tomando como marco el contexto de derrota política de las izquierdas en América Latina, en el que germinaba un naciente cúmulo de reflexiones en clave de teoría política, comencemos ahora la tarea de recuperar las distintas contribuciones que se realizaron por aquellos años en materia de conceptualización sobre el Estado.

Podemos iniciar entonces el itinerario de este artículo revisitando uno de los libros más célebres de Norbert Lechner -que constituye además un clásico de la teoría política latinoamericana-, donde desplegó su mirada crítica sobre el dependentismo: La crisis del Estado en América Latina, publicado originalmente en 1977. En el segundo capítulo de aquel trabajo, titulado precisamente La cuestión del Estado en el capitalismo dependiente, el autor se dedicó de forma específica a realizar un balance sobre los logros y 
vacancias de las teorías de la dependencia en sus análisis de las sociedades de la región. Lechner advirtió allí que, a diferencia del "desarrollismo", los estudios sobre la dependencia no habían logrado una traducción en la arena política, por lo cual se concentró en encontrar una explicación al respecto. Introdujo a modo de balance, transcurridos por aquel entonces diez años de la publicación original del texto seminal de Fernando H. Cardoso y Enzo Faletto Dependencia y desarrollo en América Latina, el núcleo de sus críticas al dependentismo. Sostenía Lechner:

Hoy, revisando los múltiples estudios sobre <situaciones de dependencia >> podemos apreciar la fecundidad del enfoque, pero también sus trabas (...) Los estudios sobre la dependencia, diría yo, no han logrado determinar lo que era justamente la finalidad del análisis: <<las vinculaciones económicas y político-sociales que tienen lugar en el ámbito de la nación >>. Es decir, que no han logrado establecer la mediación entre Sociedad Civil y Estado en América Latina. Plantean el problema político central del continente, pero no lo resuelven. (Lechner, 2006b: 82-83).

Allí, bajo una inspiración eminentemente gramsciana, el politólogo chileno-alemán insertaba en el debate sobre la dependencia un problema sustantivo en la tradición marxista, pero también crucial para la comprensión de las singularidades latinoamericanas: la relación Estado-Sociedad Civil. Pues las mediaciones que vinculan lo económico y lo político en el plano nacional resultan un aspecto vital en vistas de producir una intelección precisa de los procesos sociales. Aparecía allí, por lo tanto, una primera insinuación crítica de Lechner hacia el dependentismo. Según su perspectiva, en los enfoques de la dependencia había sido insuficiente el abordaje de las mediaciones características de las sociedades latinoamericanas. Y en particular, había sido escasamente estudiada aquella que se erige como la principal mediación social en nuestras tierras entre lo económico y lo político: el Estado (entendido, nuevamente bajo inspiración gramsciana, en un sentido "ampliado").

Por esa razón, no resultaba casual que uno de los cuestionamientos más importantes de Lechner hacia el dependentismo se hallara en la escasa atención colocada en el Estado, o bien, en la ausencia de un tratamiento específico sobre la estatalidad, asumiendo en su lugar una concepción de su existencia qua aparato estatal. La identificación de Estado con aparato de Estado y con acción gubernamental, colocaba una barrera infranqueable a la posibilidad de investigar el rol del Estado en el desarrollo del capitalismo, así como también su naturaleza en la relación Estado-Sociedad Civil, en su especificidad latinoamericana. Así expresaba el propio Lechner tal impedimento: 
[...] [en las teorías de la dependencia] se considera la existencia del Estado nacional como un hecho históricamente dado y-desde el punto de vista

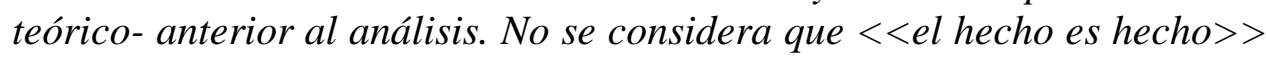
y que falta investigar la constitución del Estado en América Latina en mediación con el desarrollo del capitalismo. Inconsciente del problema de la articulación interna entre la estructura económica y su organización política se toma al Estado por lo que aparece: la burocracia civil y militar. El Estado es visto sea como interlocutor nacional frente al capital extranjero, sea como fortaleza del capital extranjero para dominar el país. En ambos casos el Estado es limitado y cosificado en aparato estatal. No se analiza al Estado como una esfera social, reduciéndolo así a un mero instrumento [...]. (Lechner, 2006b: 96; énfasis nuestro).

Esto significaba que se volvía necesario un ejercicio de conceptualización y comprensión del fenómeno estatal, con el propósito de captar un doble movimiento. Por un lado, el lugar del Estado en economías que se han insertado plenamente y de un modo subordinado en el mercado mundial. Por el otro lado, el de la estatalidad latinoamericana como forma de mediación social que garantiza el ejercicio de la dominación frente a sociedades débiles, constitutivamente dispersas en cuanto a los componentes que las integran.

Ahora bien, tal captación del doble movimiento característico de las sociedades de la región debe radicar, según Lechner, en una reflexión crítica sobre la forma en que la obra de Marx ha sido recuperada por la intelectualidad de izquierdas para el análisis latinoamericano. Pues los supuestos principales de los que partió el autor de El capital, no necesariamente se cumplen a la hora de abordar los problemas de América Latina. Eso invitaba al intelectual alemán naturalizado chileno a regresar una vez más a la particular relación Estado-Sociedad Civil que es propia de nuestra región. Decía Lechner:

El análisis de Marx se basa en dos supuestos: 1) delimitación de la Sociedad Civil a un espacio nacional; y 2) implantación total de las relaciones capitalistas de producción (...) En cambio, lo característico de la situación de dependencia es justamente la ausencia de estos supuestos. En América Latina, 1) la estructura económica desborda el territorio nacional, dependiendo del movimiento del mercado mundial, y 2) las relaciones capitalistas de producción, siendo predominantes, reproducen y producen relaciones de producción pre-capitalistas. Ambos elementos, tanto la dependencia del mercado mundial como la heterogeneidad estructural, distinguen sustancialmente la relación entre Sociedad y Estado en América Latina de la situación que tenía en vista Marx. (Lechner, 2006b: 103-104; énfasis nuestro). 
Las sociedades latinoamericanas se caracterizan entonces por la combinación de dos elementos que están indisolublemente ligados. Por un lado, en América Latina predomina una hegemonía externa, producto de que el motor de su dinámica histórica se encuentra en el proceso mundial de valorización del capital. Por el otro lado, la convivencia de diversos tipos de relaciones sociales de producción constituye, tal como ha sido mencionado en el capítulo anterior, una heterogeneidad estructural, que repercute en la ausencia de una praxis social común. Hegemonía externa y heterogeneidad estructural, así, son las dos características distintivas de las sociedades latinoamericanas. La dificultad que se presenta en el estudio de América Latina es, por lo tanto, la incongruencia provocada por la situación de dependencia, entre el espacio económico y el espacio político (Lechner, 2006a: 85).

Ese dilema tiene consecuencias a la hora de comprender la naturaleza del Estado latinoamericano. Pues ante la hegemonía externa y la heterogeneidad estructural se puede observar una doble faceta del Estado en América Latina. Afirmaba Lechner al respecto:

En América Latina, el Estado se encuentra a la vez más y menos excluido, más y menos dependiente de la Sociedad Civil, según consideremos uno u otro elemento. Considerando que el proceso de acumulación pasa por el circuito del mercado mundial, el poder político sólo puede ser un organizador y un garante del proceso de producción. El Estado se encuentra más excluido de la Sociedad en cuanto el motor del proceso económico radica fuera del territorio estatal, en el mercado mundial (...) En cambio, si consideramos la heterogeneidad estructural, el Estado aparece menos excluido y menos dependiente de la esfera económica (...) No se ha constituido una burguesía como clase nacional, clase nacionalmente dominante; el proceso económico requiere la tutela política y los grupos sociales actúan mediante la <<intervención estatal >>. De ahí que el Estado aparezca menos dependiente (...) En este sentido, la <<intervención>> estatal es preponderante y de gran autonomía. Si la dependencia del mercado mundial nos muestra un $<\langle$ Estado débil $\rangle>l a$ heterogeneidad estructural nos muestra un <<Estado fuerte $>>$ (Lechner, 2006b: 104-105).

Es decir que se trata de una especie de identidad bifronte propia de la estatalidad autóctona, que, en cierta medida, explica el excesivo nivel de concurrencia estatal que ha singularizado a los procesos políticos en la región. La interpretación de Lechner sobre el Estado en América Latina nos introduce la centralidad de lo estatal y lo político como momento de síntesis de lo disperso. Síntesis que de lo contrario habría encontrado mayores dificultades a la hora de producir su lugar de unificación. Extremando los argumentos, 
podríamos afirmar que quizá, aunque sea en parte, Lechner nos propone una justificación de aquella "sobre acentuación” en lo estatal que caracterizara a los propios “desarrollistas”, o bien, nos explica por qué con tanta naturalidad éstos últimos podían vislumbrar, sin perder con ello un apego bastante próximo a la realidad, la posibilidad de depositar concentradamente en el Estado las expectativas de un proyecto alternativo de desarrollo (aun cuando no explicitaran ni problematizaran las razones por las cuales les resultaba factible hacerlo).

Pues bien, para concluir este breve repaso por los aportes teóricos de Norbert Lechner en torno a los problemas de la dependencia y el desarrollo en la región y su vinculación con lo estatal en su libro La crisis del Estado en América Latina, debemos señalar que a través de ese trabajo cumplió la tarea de presentar, según nuestro punto de vista, un problema fundamental de la temática que allí aborda. Y lo hizo por medio de un balance crítico de la producción intelectual dependentista. El interrogante que ha dejado planteado se expresa en las siguientes palabras, que le pertenecen al propio politólogo chileno-alemán: “(...) ¿cuál es la mediación entre lo económico y lo político? (...) No se encuentra en los estudios sobre la dependencia la referencia a una totalidad, que permita establecer las mediaciones entre los procesos económicos y los procesos políticos” (Lechner, 2006b: 108; énfasis nuestro). El autor culmina el capítulo del libro al cual nos hemos referido con un recorrido por posibles modos de integración social en América Latina en el marco de sociedades nacionales que frente a su heterogeneidad estructural han encontrado serios obstáculos para construir una identidad colectiva. Creemos que aquella reflexión final no se corresponde con, ni tampoco agota, la riqueza de las preguntas que deja planteadas. En cualquier caso, la profundización de un abordaje más sistemático del vínculo entre Estado-Sociedad Civil y de las mediaciones entre lo político y lo económico en el marco de sociedades atravesadas por una hegemonía externa y una heterogeneidad estructural, resultan indicaciones que pueden abrir lugar a un vasto y necesario programa de investigación sobre las formas contemporáneas de la dependencia en América Latina.

\section{Agustín Cueva: el Estado latinoamericano bajo el prisma leninista del imperialismo}

Por su parte, también el sociólogo ecuatoriano Agustín Cueva elaboró en este contexto, de fines de los setenta y comienzos de los ochenta, algunos ejes de reflexión acerca del Estado que resultan de sumo interés. El primero de esos ejes se vincula con la pregunta acerca de la existencia (o no) de una teoría general del Estado. Esto es: en qué medida lo estatal puede ser conceptualizado en el mismo nivel de 
abstracción, por ejemplo, que el modo de producción. El segundo eje tiene que ver con la especificidad del Estado en América Latina, es decir, su naturaleza y sus determinaciones.

Comenzando por el primer eje, Cueva se pregunta si es correcto evaluar la posibilidad de dilucidar la problemática del Estado latinoamericano a partir de una teoría del Estado "en general". Pues, en definitiva, sostiene, sería como afirmar que a un modo de producción determinado le corresponde un tipo de Estado. Es decir, cuestiona la fertilidad teórica de afirmar que al modo de producción capitalista le corresponde un Estado capitalista con el fin de reproducir dicho modo de producción como tal. El interrogante se vincula con el nivel de pertinencia de un grado alto de abstracción, en este caso para el análisis de las superestructuras. Es que ciertamente, la función del Estado capitalista es reproducir en escala ampliada ese modo de producción. En definitiva, ello es lo único que define a dicho Estado como tal. Mas su expresión formal, su presencia concreta, es imposible de deducir en un nivel tan elevado de generalidad.

$\mathrm{Al}$ mismo tiempo, el autor de El desarrollo del capitalismo en América Latina, inscribe sus reflexiones sobre el aspecto formal de las superestructuras, en su inserción en el capitalismo como sistema mundial, un punto que guarda una especial vinculación con la temática de la dependencia y el imperialismo (relación para nada casual, ya que Cueva siempre se mantuvo apegado a la concepción del Lenin de 1916). Pues desde su perspectiva, las tareas a cumplir por la dimensión estatal no pueden ser desvinculadas del desarrollo capitalista que se produce al interior de una nación. La cual, por supuesto, se relaciona tanto con la intensidad de la lucha de clases al interior de sus fronteras como con su ligazón al sistema imperialista. En palabras del propio Cueva:

Y es que el Estado capitalista sólo existe en cuanto forma ya concreta, como Estado capitalista de determinada formación económico social, con todas las determinaciones histórico-estructurales allí presentes, resultado tanto de un específico desarrollo interno como del lugar que cada formación ocupa en el seno del sistema imperialista. $Y$ es precisamente la configuración de cada formación la que determina en última instancia la forma del Estado capitalista, de acuerdo con el grado de intensidad y desarrollo de las contradicciones acumuladas en su interior, de la posibilidad objetiva de atenuación o acentuación de las mismas, y de las tareas (funciones concretas) que de allí se desprenden para la instancia estatal. (Cueva, 1981: 259; énfasis del original). 
La forma concreta del Estado capitalista se vislumbra, según Cueva, al nivel de la formación económicosocial. Aparece en ese sentido una cercanía con respecto a las reflexiones que en materia de teoría del Estado realizara René Zavaleta (sobre quien nos detendremos más adelante) en los comienzos de los años ochenta. Dicho intelectual boliviano postula la infertilidad de una teoría general del Estado, pues la considera impertinente en cuanto al nivel de abstracción necesario para analizar ese fenómeno. De tal manera, propone la utilización de categorías intermedias que permitan describir con mayor rigurosidad la autonomía de lo político. En esa sintonía, en su artículo titulado El Estado en América Latina, Zavaleta afirmaba:

Ahora bien, el ciclo de rotación, o la generalización de la forma valor, o el desdoblamiento de la plusvalía, nos dan la medida en que se obtienen sus resultados, es decir, el grado del Estado o la dimensión de totalización, pero no nos explican el carácter de los mismos (...) En otros términos, es por esto que las categorías intermedias, predominantemente históricas, como formación económico-social, bloque histórico, superestructura, hablan de la diversidad o autoctonía de la historia del mundo y en cambio el MPC [modo de producción capitalista] considerado como modelo de regularidad se refiere a la unidad de esta historia o mundialización de la historia. Esto mismo es sin duda un obstáculo, no meramente argumental para una "teoría general" (Zavaleta, 1990a: 168-169; énfasis del original).

Por supuesto, este aspecto está vinculado con el segundo eje de reflexión sobre el fenómeno estatal que mencionáramos en la producción de Cueva por aquellos años: el Estado en América Latina. Pues tanto él como Zavaleta, en definitiva, de manera explícita o implícita, cuando señalan la impertinencia de una teoría general del Estado, están pensando en la necesidad de profundizar el análisis sobre lo estatal en función de las características concretas que aquél asume en la realidad latinoamericana.

En esta dimensión, el sociólogo ecuatoriano otorga un papel protagónico al carácter dependiente de las sociedades de la región. Es que para el autor de Entre la ira y la esperanza, la definición del Estado y sus características no puede escindirse del rol que esa nación desempeña en el sistema mundial. Pues las reflexiones de Cueva sobre lo estatal se enmarcan en la teoría leninista del imperialismo. La especificidad latinoamericana está dada, en parte, por su inserción en un sistema imperialista, el cual tiene fuertes repercusiones en el establecimiento de funciones estatales. 
Al mismo tiempo, existen otros dos factores que van a influir poderosamente en la naturaleza del Estado capitalista en América Latina. Nos referimos, por una parte, a la forma en que en nuestros países se produce la construcción de los Estados nacionales. Esa vía reaccionaria, tal como la describiera el propio Cueva (2009) en El desarrollo del capitalismo en América Latina, dotada de signos autoritarios y despóticos para garantizar la unificación e integración económica, va a impactar en el desenvolvimiento de las tareas estatales. Por otra parte, hablamos de sociedades heterogéneas donde, al igual que señaláramos junto a Lechner en el apartado anterior, están articulados distintos modos de producción y, por lo tanto, se conforma una compleja estructura de clases.

Pues bien, el carácter dependiente y subdesarrollado de América Latina, repercute en todos los niveles de la sociedad, incluido en la esfera estatal, estructurando sus competencias y funciones. Así lo define Agustín Cueva, inscribiendo sus reflexiones en la tesis leninista de la agudización y acumulación de contradicciones en las áreas periféricas del capitalismo:

[...] las áreas de mayor acumulación de contradicciones ("eslabones débiles") coinciden con el espacio de los países llamados subdesarrollados y dependientes. Lo que, es más, creemos legítimo sostener que es aquella acumulación la que define el carácter de estos países, no sólo en lo que a su base económica concierne sino también y correlativamente en lo que atañe a su instancia estatal. En efecto, ésta se constituye como una superestructura sobrecargada de "tareas" en la medida en que: a) tiene que asegurar la reproducción ampliada del capital en condiciones de una gran heterogeneidad estructural (...); b) tiene que llevar adelante ese proceso de reproducción en medio de un constante drenaje de excedente económico hacia el exterior (...); y c) tiene que imponer cierta "coherencia" a un desarrollo económico-social inserto en la lógica general de funcionamiento del sistema capitalista imperialista, cuando a veces ni siquiera está concluida la tarea de integración de un espacio económico nacional y de la nación misma (Cueva, 1981: 260; énfasis nuestro).

Resulta de especial interés, desde nuestro punto de vista, cómo el sociólogo ecuatoriano en la cita anterior articula sus aportes sobre el Estado con el problema de la dependencia. Pues, en sintonía con su crítica al dependentismo realizada tempranamente (en 1974, en un artículo titulado Problemas y perspectivas de la teoría de la dependencia), Cueva (1979) supo explorar esa relación (Estado-dependencia), considerando de forma consciente que ella había sido relativamente descuidada, en sus distintas vertientes, por las teorías de la dependencia. 
René Zavaleta: el Estado, entre la forma primordial y la determinación dependiente

Nos toca ahora desplazar nuestra atención hacia otro intelectual que destinó grandes esfuerzos teóricos a reflexionar sobre lo estatal en la intersección de los años setenta y ochenta. Nos referimos a René Zavaleta Mercado, ya mencionado más arriba en este estas páginas. Este pensador boliviano dedicó numerosos pasajes de sus trabajos -y también artículos completos-, a la comprensión del fenómeno estatal en sociedades dependientes. Si bien muchas de sus definiciones teóricas no tienen exclusivamente un alcance latinoamericano, creemos que de cualquier manera ellas abrevan en una realidad como la de nuestra región, que se mostraba “disponible” frente a los razonamientos zavaletianos.

En un artículo publicado en 1982, titulado Problemas de la determinación dependiente y la forma primordial, Zavaleta sostenía que la dependencia se trata de un "hecho particular". Es decir, que no existe un único modo de procesar la determinación dependiente, sino de acuerdo con un conjunto de características de cada formación económico-social, en el marco de fluctuaciones en el "grado de emisión" del "flujo externo", las diversas naciones procesan de formas diferenciadas la dependencia. En ello desempeña un rol sustancial aquello que Zavaleta llamara el "auge democrático de la multitud", o bien, “el grado de autodeterminación de las masas”. Por eso, según el intelectual boliviano, la potencia democrática del pueblo resulta la medida negativa de la dependencia.

Ahora bien, en el marco de esas reflexiones, en un artículo publicado un año después, aparece con centralidad el fenómeno estatal. Nos referimos al trabajo, ya mencionado más arriba, que llevara por título El Estado en América Latina. Allí, irrumpe el interrogante por el carácter del Estado en nuestra región y por la medida en que, de acuerdo con nuestras formaciones económico-sociales, la dimensión estatal podía desempeñar un papel progresivo en la lucha de clases. En el artículo de referencia, Zavaleta plantea esa pregunta al detectar, precisamente, la singularidad de que, en diversas ocasiones de la historia latinoamericana, el Estado supiera cumplir un rol tan transformador como los movimientos de masas, cuestionando de esa forma la concepción inmediatista según la cual éstos últimos serían naturalmente portadores de la democracia (Zavaleta, 1990a: 163). Tal interrogante lleva a Zavaleta a plantear teóricamente el problema de aquello que él denomina la "ecuación social". Una categoría en la que se puede divisar con claridad meridiana el filón gramsciano que está presente en los últimos textos del autor de Lo nacional-popular en Bolivia: 
La manera abigarrada que tienen las cosas al entrelazarse propone por sí misma el concepto de ecuación social o sistema político, que es una de las acepciones que daba Gramsci al bloque histórico: el grado en que la sociedad existe hacia el Estado y lo inverso, pero también las formas de su separación o extrañamiento. El análisis mismo del Estado como aparato y como ultimidad clasista sugiere la forma de su relación con la sociedad civil. Por razones propias de cada caso, hay ecuaciones en las que la sociedad en más robusta y activa que el Estado, ecuaciones donde el Estado parece preexistir y predominar sobre la sociedad, al menos durante períodos determinados y sistemas donde hay una relación de conformidad o ajuste. Esa relación supone un movimiento y por eso es tan absurdo hacer clasificaciones finales sobre ello. La cualidad estatal, no estatal o intermedia de una instancia depende de su momento. (Zavaleta, 1990a: 177; énfasis nuestro).

Zavaleta llama "ecuación social” a las múltiples formas de entrecruzamiento, separación o extrañamiento que existen entre Estado y sociedad civil (o mejor, siguiendo más estrictamente al autor, entre la sociedad civil, las mediaciones y el momento político-estatal). Al igual que lo manifestaba Lechner, este intelectual boliviano hace referencia a la dislocación que produce la determinación externa (en otros términos, la dependencia) en la "ecuación social". Y ello ocurre en diferentes niveles. Es decir, no solo como producto del "grado de emisión" según la coyuntura internacional, sino también de acuerdo con la forma particular en que se llevan a cabo las constricciones y la injerencia externas en cada plano nacional. Pues como sostiene Zavaleta “(...) el grado de autonomía del acto hegemónico es casi un coeficiente del desarrollo estatal, porque el Estado debe intervenir más donde hay menos desarrollo de la sociedad civil.” (Zavaleta, 1990a: 128). Así, según como fuera procesada la dependencia y en acuerdo con el modo en que ella se produjera, en aquellos países donde existió un mayor despliegue de la sociedad civil, el Estado pudo cobrar mayor autonomía, y viceversa.

De cualquier manera, el énfasis de Zavaleta se coloca en remarcar el carácter aleatorio de las mediaciones y las instancias. Por eso, resulta imposible desde su punto de vista pensar en una idea inmutable de Estado que lo considere desde un elevado nivel de generalidad en cuanto a su accionar en la sociedad, como progresivo o reaccionario. Más bien, el autor de El poder dual insiste en que la especificidad de América Latina, en función de las características de sus formaciones económico-sociales, en ciertos contextos ha podido encontrar en el Estado un lugar progresivo. Porque frente a la dislocación provocada por la determinación externa, junto con el fenómeno del abigarramiento social, el Estado se ha erigido en determinadas circunstancias como único lugar de unidad de lo popular. Ante la debilidad del acto 
hegemónico, en naciones construidas "desde arriba" y en el marco de una inserción subordinada en el mercado mundial capitalista, ha sido posible que el pueblo encuentre serias dificultades para unificarse a sí mismo. Ello, por tanto, le ha otorgado un espacio singular a la instancia estatal. A contrapelo, una lectura que llegara a hipostasiar el significado de las diversas instancias que componen cada "ecuación social" implicaría, en palabras de Zavaleta, "la ruina del análisis político", o incluso, "una historia paralizada".

Esto nos devuelve nuevamente a lo que sosteníamos, en sintonía con ciertos razonamientos de Agustín Cueva arriba reseñados, acerca de la posibilidad (o no) de producir una teoría "general” del Estado. Si las "ecuaciones sociales" resultan divergentes y si son el producto de la complejidad del desarrollo histórico, la construcción de una teoría del Estado reductible a ciertos rasgos efectivamente existentes en las sociedades capitalistas como "modelo de regularidad", se presenta como una tarea infructuosa. Pues dichos rasgos se estancan en un carácter meramente descriptivo, impotente para avanzar sobre aspectos sustanciales de la estatalidad. En palabras de René Zavaleta:

La ecuación o el bloque, tiene entonces elementos verificables de historicidad y azar, no es una estructura predicha. Es una obra de los hombres materialmente determinados, algo que pudo haber sucedido de manera distinta a cómo sucedió. Como en todo modelo superestructural, podemos obtener algunas series causales o líneas de agregación, pero en último término la teoría del Estado, si es algo, es la historia de cada Estado. Lo que importa, por tanto, es el recorrido de los hechos en la edificación de cada Estado (Zavaleta, 1990a: 180).

Otro aporte interesante en Zavaleta, vinculado al concepto de "ecuación social", tiene que ver con una preocupación que resulta medular en varios de sus últimos trabajos: el problema de la revolución en sociedades nacionales signadas por situaciones de dependencia. Pues la hipótesis que el intelectual boliviano pretende refutar es aquella según la cual la existencia de un excedente económico permite mejores condiciones para la emergencia de una crisis revolucionaria. Por el contrario, Zavaleta tiende a afirmar que la relación que existe entre excedente y disponibilidad, resulta una “disgresión compleja”. Y en ese sentido, en Problemas de la determinación dependiente y la forma primordial, concluía:

Eso significa que si la reducción de la disponibilidad al excedente económico es una variante pirrónica de corte economicista, su reverso, es decir, la disponibilidad entendida como un acto infuso, nos llevaría a 
entenderla como una especie de entrega mesiánica (...) La situación revolucionaria o si se quiere la crisis nacional general como catástrofe propia de nuestra época es una forma típica de disponibilidad determinativa que tiene que ver sólo de manera mediata con su causa económica (...) Es la profundidad de la ruptura de la episteme colectiva y el estado de fluidez consiguiente lo que en verdad importa. (Zavaleta, 1990b: 133; énfasis nuestro).

Afirmábamos antes de la última cita que la relación entre excedente y disponibilidad se relaciona con el concepto de "ecuación social", pues de lo contrario éste último se presentaría como indeterminado. Para Zavaleta, la relación Estado-Sociedad civil se establece dentro de condicionamientos estructurales, entre los cuales, uno de ellos, es precisamente la disponibilidad del excedente. Entonces, la posibilidad de constitución de mediaciones fuertes, que logren acercarse a la conformación de un "óptimo" entre Estado y Sociedad Civil, no es posible sin la existencia de un excedente (razón por la cual, en Zavaleta, la versión “culturalista" de Gramsci y del concepto de hegemonía es sepultada). Así explicaba este aspecto en Lo nacional-popular en Bolivia:

Si por mediación se entiende la transformación de la furia del oprimido en una parte del programa del opresor, lo cual es después de todo una relación hegemónica, es obvio que la mediación es tanto más posible cuanto más amplio es el excedente porque representar al Estado ante la sociedad y a la sociedad ante el Estado es algo que contiene dinero, prebendas o gratificaciones. (Zavaleta, 2008: 35).

En síntesis, en la batería conceptual que acuña Zavaleta sobre la base, fundamentalmente, de sus lecturas en torno a la experiencia histórica de América Latina, el análisis de la dependencia no deja lugar para un reduccionismo economicista. Ello repercute en (y a la vez, parte de) un interés especial por lo político y lo estatal. En ese sentido, la categoría de "ecuación social” es una llave teórica imprescindible en Zavaleta para comprender la especificidad de las formaciones económico-sociales. Pero, ante todo, ella permite pensar el lugar de la estatalidad, en tanto lo estatal no ocupa un espacio residual en la intelección del conjunto social, sino que representa un aspecto fundamental en su particular vinculación o extrañamiento con la sociedad civil. El excedente, sin dudas, es una dimensión crucial para comprender las posibilidades y modos de articulación entre Estado y Sociedad Civil, pero no representa una explicación suficiente. En tal caso, en Zavaleta, la conjugación de un análisis del excedente y de la historia de edificación de cada 
Estado -como en el ejercicio práctico llevado a cabo en Lo nacional-popular en Bolivia-, constituye su aporte teórico y metodológico para reflexionar sobre el fenómeno estatal en sociedades dependientes.

\section{Marcos Kaplan: el "Leviathan criollo"}

Pues bien, otro intelectual que dedicó importantes trazos de sus escritos en la bisagra de las décadas del setenta y el ochenta a reflexionar en torno a la dimensión estatal fue el argentino Marcos Kaplan. En varios de sus más importantes trabajos el Estado es un aspecto en el que concentra la atención a la hora de explicar la realidad histórica y la dependencia de América Latina. En ese sentido, en el comienzo de uno de sus textos fundamentales, titulado Aspectos del Estado en América Latina, Kaplan es contundente sobre la centralidad del fenómeno estatal en el abordaje de la dependencia y el desarrollo: "Los problemas del desarrollo y la crisis política de América Latina han colocado en el centro del interés y de la discusión la cuestión de las relaciones entre la sociedad y el Estado, la naturaleza y funciones de éste, su dependencia y su autonomía relativa respecto a la primera.” (Kaplan, 1981: 11).

Un primer elemento sobre el que focaliza Kaplan con respecto a lo estatal remite, como punto de partida, a una cuestión extensamente debatida en el seno de la tradición marxista: la relación entre estructura y superestructura. Cuestionando tanto la idea de correspondencia necesaria como la de un condicionamiento unidireccional, Kaplan se encarga de señalar la relación dialéctica que existe entre ambas esferas. Con sus propias palabras:

Es indispensable entonces superar las formas de reduccionismo que otorgan primacía exclusiva y excluyente a lo infraestructural o a lo superestructural, y caen en el punto muerto de la dependencia o de autonomía absoluta de lo político, simplificando groseramente la realidad.

Se trata de explorar la naturaleza de la relación dialéctica entre infraestructura y superestructura como dos momentos igualmente condicionantes y determinantes y, más en general, los lazos e interacciones entre las diversas instancias y polos generadores, estructuradoestructurantes, que en conjunto configuran y mueven una sociedad. (Kaplan, 1981: 23-24; énfasis del original).

Aquel aspecto que Kaplan insiste en remarcar, entonces, es la crítica tanto al "reduccionismo" como al "politicismo". Es decir, a la hora de analizar la cuestión estatal busca impugnar la noción según la cual la economía tiene inobjetable primacía sobre la política, al punto de concebir esa relación bajo la forma de 
una determinación. Pero, al mismo tiempo, rechaza aquellas miradas a partir de las cuales el Estado se presenta como exento de determinaciones. En ese sentido, este intelectual argentino, quien fuera profesor en la Universidad Nacional Autónoma de México durante largos años de su vida, explicaba la relación entre estructura y superestructura de la siguiente manera:

El condicionamiento y la determinación infraestructurales no se ejercen de manera automática, mecánica, inmediata, sino en última instancia, en grandes líneas, a largo plazo. Se manifiestan como, y se ejercen y despliegan a través de y por intermedio de las múltiples formas y procesos correspondientes a la llamada superestructura: tradiciones históricas, ideológicas, costumbres, prácticas, culturas políticas, profesiones políticas organizadas, papeles políticos determinados, aparatos estatales, circunstancias internacionales. La dependencia de lo superestructural hacia lo infraestructural es siempre relativa. Los componentes e instancias de la superestructura, lo político y el Estado, una vez constituidos, tienden a adquirir autonomía relativa, lógica específica, movimiento propio y papel motriz respecto a la infraestructura socioeconómica, sobre la cual pueden ejercer una acción igualmente determinante y condicionante (Kaplan, 1981: 24-25).

Así, Kaplan considera que la especificidad y la eficacia de cada nivel o instancia de lo social, depende de su ubicación en la totalidad, mas no está determinada por ella. Pues en el seno de la totalidad existe una multiplicidad de posibilidades en cuanto a la articulación de las instancias, que nos hablan de su falta de coherencia.

Este último aspecto nos parece central en el planteo de Kaplan, porque otorga un especial significado al lugar de lo político y lo estatal. Dicho nivel específico guarda en la lectura de este intelectual argentino un papel privilegiado como motor de la dinámica histórica, articulado a una totalidad, pero imposible de ser subsumido plenamente a ella. Así desarrollaba este argumento en Aspectos del Estado en América Latina:

La superestructura -y en particular lo político- no es simple reflejo de la infraestructura. Expresa sus caracteres y dinamismos y sus tendencias de desarrollo, pero puede actuar en un sentido de refuerzo o modificación, de aceleración o de bloqueo, y modelar así la forma de la sociedad y el curso de la evolución histórica. Lo superestructural concientiza, organiza y moviliza, ideológica y políticamente, a los grupos, y a través de ello, incide en todo lo que ocurre al nivel de las fuerzas productivas, de las relaciones 
sociales, de los conflictos de clases. Lo esencial del movimiento histórico se desarrolla en la superestructura y en la instancia política, que en cierto sentido convierten a la infraestructura en su objeto y en su instrumento de acción (Kaplan, 1981: 25; énfasis nuestro).

En ese sentido, Kaplan subraya en la instancia de lo político un problema también clásico en la tradición marxista, que bien puede remitirnos largamente a El 18 Brumario de Luis Bonaparte del propio Marx. Nos referimos a la autonomía relativa del Estado. Al referirse a lo estatal, señala que la identificación absoluta entre Estado y clases dominantes resulta imposible. Afirma que, en lugar de una relación mecánica o inmediata entre ambos, más bien es correcto hablar de la necesidad de su autonomización relativa.

De esa manera, Kaplan cuestiona la visión instrumentalista del Estado. Pues desarrolla una crítica a la idea de manipulación incondicional y exterior de la esfera estatal por las clases dominantes. En sus propios términos:

El Estado no puede presentarse como mero instrumento de una clase dominante y defensor de sus intereses y del sistema. Es indispensable que en parte se presente y en parte realmente se sitúe y opere como instancia autonomizada y superior a las clases y grupos, fuerza dominante de la sociedad, aparato de dominación y administración respecto a todas las clases, potencia extraña a sus preocupaciones inmediatas. (Kaplan, 1981: 109; énfasis del original).

Por otra parte, Kaplan se aproxima a una concepción del Estado que ya estaba presente en Marx. Nos referimos a aquella según la cual éste hacía alusión a "la síntesis de la sociedad civil bajo la forma de Estado". El intelectual argentino, si bien afirma que lo estatal no es expresión de una racionalidad trascendente o inmanente de la sociedad, sí sostiene que resulta un producto de ella, y que constituye "su resumen oficial y simbólico.” (Kaplan, 1981: 48-49). Pero aun cuando la lucha entre clases y grupos en la sociedad se resume en el Estado, vale aclarar que, para Kaplan, no se trata de un resumen que adopta la modalidad de un reflejo, sino que se manifiesta de forma refractaria y transpuesta. (Kaplan, 1981: 58). Tal como señalara Zavaleta en El Estado en América Latina, lo hace como una "síntesis calificada", o también, usando sus propias palabras, dando su propio color o señal al mensaje emitido por la sociedad. 
Concentrando la mirada más específicamente en América Latina, Kaplan observa la singularidad que caracteriza a la dimensión conflictual de la estatalidad latinoamericana. La conclusión a la que llega se asemeja bastante a la "sobrecarga de tareas" a la que se refería Agustín Cueva. La crisis de hegemonía que signa a la región convierte al Estado, según el intelectual argentino, en un escenario de pujas permanentes. Así lo explicaba en su libro titulado Sociedad, política y planificación en América Latina:

En virtud de la crisis de hegemonía, ninguna clase o fracción domina total o exclusivamente al Estado, ni puede usarlo de modo irrestricto en función de una estrategia definida y coherente. Todas las clases, capas y sectores pujan sobre y dentro del Estado, en mayor o menor grado y con fuerza variable, para lograr satisfacer sus intereses sectoriales. La acción estatal parece convertirse a menudo en mera resultante inestable del juego de presiones múltiples, que contribuyen a desgarrarla, irracionalizarla y paralizarla. (Kaplan, 1980: 18-19).

Esa definición acerca de la lucha permanente que libran los múltiples actores de la sociedad "sobre y dentro del Estado" da por tierra con la idea de una manipulación exclusiva de la esfera por una clase o fracción de clase. Y abre lugar a un conjunto de funciones y complejidades, que Kaplan en Aspectos del Estado en América Latina retrataba de la siguiente manera:

Asume y ejerce una función de mediación y arbitraje entre los grupos internos y externos, entre la sociedad nacional y las metrópolis, entre la autonomía y la dependencia. Existe y tiene razón de ser en función de las realidades nacionales. Debe tener en cuenta los particularismos de sus matrices y dinámicas sociohistóricas; los requerimientos de su racionalidad de conjunto; las necesidades de reproducción y reajuste del sistema; las relaciones de los grupos hegemónicos y de las clases dominantes del país con sus equivalentes de las metrópolis y con las otras clases y fracciones del respectivo país, y las posibilidades de divergencias, tensiones y conflictos entre todos estos actores (Kaplan, 1981: 102).

De ese modo, si hay algo que parece caracterizar a las "ecuaciones sociales" en América Latina es precisamente cierta debilidad de la sociedad civil frente al vigor del "factor externo". Y al mismo tiempo, por ende, una hiperactividad estatal, junto con una situación de plena concurrencia de las clases en el Estado para morigerar las consecuencias del flujo exterior. Tal la dislocación causada por las situaciones de dependencia sobre la posibilidad de construcción de un "óptimo" entre Estado y Sociedad Civil. En ese sentido es que Kaplan en Aspectos del Estado en América Latina acuña la figura del "Leviathan criollo". 
Y a su vez, es la razón por la cual, desde su perspectiva, el estudio y la comprensión del Estado en nuestra región asumen un papel primordial.

Al mismo tiempo, las "ecuaciones sociales" latinoamericanas repercuten en el problema de la planificación estatal. Pues los desniveles entre regiones, la estructura económica tan polarizada y rígida, y la creciente absorción de tareas por el Estado, contribuyen según su perspectiva, a una "supercentralización y verticalidad", tanto geográfica como funcional, de la administración pública. (Kaplan, 1976: 38).

Ahora bien, para finalizar este recorrido por los aportes de Kaplan, podemos señalar que, sobre la base de las definiciones arriba reseñadas, este intelectual argentino intenta explicar los motivos por los cuales en muchas ocasiones el Estado asumió en América Latina un rol sustantivo en el direccionamiento de los procesos de desarrollo autónomo. Es decir, busca explicar aquello que para muchos pensadores “desarrollistas" se manifestaba como un elemento de hecho. En palabras del propio Kaplan:

El Estado es el único que puede asumir la solución de los problemas de armonía y conflicto del país o de algunos de sus sectores con la potencia hegemónica, sus corporaciones multinacionales y la de otros países desarrollados, y la regulación de las relaciones entre todas ellas. En sus políticas nacionalistas, el Estado busca además canalizar hacia el exterior fuerzas, reivindicaciones y tendencias internas que son o pueden volverse amenazantes para el sistema, y contar con bases nacionales movilizables que refuercen la capacidad de maniobra del grupo gobernante respecto a los Estados y corporaciones de la potencia hegemónica y de los países desarrollados, permitan reducir o renegociar la dependencia, y al mismo tiempo fortalecen la autonomía relativa del Estado y del grupo gobernante respecto a las clases altas nacionales. (Kaplan, 1981: 103-104).

Sin embargo, lo interesante en el planteo de Kaplan es que la "hiperactividad estatal" no se orienta siempre en una misma dirección, sino que depende de relaciones de fuerzas que, en el caso de los países latinoamericanos, no se restringen exclusivamente al plano interno. Más bien, las fluctuaciones en la coyuntura internacional desempeñan un papel sustantivo a la hora de comprender si el Estado es capaz de asumir un rol de dirección del desarrollo autónomo, acudiendo a la movilización de sectores disponibles en el terreno nacional. Aquí el intelectual argentino de referencia coincide con Zavaleta al señalar que la situación local se transforma sustancialmente en función de las variaciones en el "grado de emisión" proveniente del exterior. Cuando éste, por motivos externos, tiende a menguar, se transforman las 
relaciones de fuerzas, y con ello, la estatalidad se muestra más permeable ante la puja de las múltiples fuerzas que se enfrentan en el plano interno. De este modo lo planteaba Kaplan en Sociedad, política y planificación:

[...] ciertas coyunturas internacionales, independientes a veces de la voluntad de las metrópolis y de los grupos internacionales, pueden crear oportunidades y opciones que son aprovechadas de diferentes maneras por los grupos hegemónicos y dominantes de los países latinoamericanos para asumir un grado relativo de independencia y un poder más o menos autónomo de decisión, y para intentar modificaciones significativas en la orientación y la configuración de las políticas internas y externas. Explican también por qué en América Latina el Estado ejerce a menudo una especie de función mediadora y arbitral entre los grupos internos y externos, entre la sociedad nacional y las metrópolis, entre la dependencia y la autonomía. (Kaplan, 1980: 55; énfasis nuestro).

\section{Reflexiones finales}

Para concluir este artículo, nos interesa realizar un señalamiento sobre los vaivenes temáticos sufridos por el marxismo latinoamericano luego de la derrota política sufrida por los sectores populares en la década del setenta.

Vale remarcar que en los años sesenta y en la primera mitad del setenta las teorías de la dependencia se constituyeron como uno de los núcleos centrales de debate en el marxismo latinoamericano. La dependencia, por tanto, se erigió como ariete de un notable cúmulo de discusiones en aquella década y media. No obstante, en la intersección de los años setenta y ochenta las reflexiones acerca la dependencia y el desarrollo aparecen un tanto desplazadas del foco de atención. Sin embargo, ello no significa que esa preocupación teórica desapareciera por completo. Más bien, creemos que tales circunstancias, en un determinado contexto político latinoamericano (el de la derrota), llevaron a un conjunto de intelectuales de la región a analizar críticamente las producciones de los dos decenios precedentes, incluyendo en ello a las teorías sobre la dependencia y el desarrollo. En algunos casos, esos cuestionamientos son formulados como una crítica, y en otros, como una autocrítica. En cualquier caso, lo que vale rescatar es que tal desplazamiento temático coincide y confluye con un abordaje teórico específico acerca de lo estatal.

Así, la dependencia y el desarrollo son inteligidos no sólo bajo la perspectiva de la inserción del "factor externo" y de la debilidad de las clases fundamentales en nuestras tierras, tal como habían sido 
predominantemente abordadas por el dependentismo. Son estudiados partiendo de esos elementos, pero pasando también a considerar el lugar trascendente que ha tenido la estatalidad en la dinámica histórica de la región. Lo cual se ha expresado, entonces, en dos sentidos. Por un lado, abriendo interrogantes en torno de lo estatal antes insuficientemente atendidos. Y por el otro, extendiendo esas preguntas hacia la especificidad latinoamericana del fenómeno, estableciendo de ese modo un vínculo con el problema de la dependencia y el desarrollo. De esa forma, la relación entre Estado y Sociedad Civil (conceptualizada por Zavaleta como “ecuación social”), tuvo un papel muy destacado en las producciones teóricas de referencia. Pues la dependencia, precisamente, al producir una dislocación de ese vínculo en América Latina, ameritaba depositar la mirada con mayor atención sobre la cuestión del Estado, en tanto éste asumía "funciones" muy distintas a las de los "modelos clásicos".

Ya entrados los años ochenta, tal como ha señalado Agustín Cueva (1988), la intelectualidad de izquierdas en América Latina comenzó a sufrir una “amnesia recurrente” en torno al fenómeno de la dependencia. Se trató de una temática que fue perdiendo lugar de forma creciente en las agendas de investigación. De esa manera, el incipiente proceso de vinculación entre los dilemas teóricos y políticos del Estado y la dependencia no pudo ser profundizado. En ese sentido, luego de haber revisado los aportes de Lechner, Cueva, Zavaleta y Kaplan y, por ende, tras haber dado cuenta de la fecundidad de sus aportes teóricos en esa materia, creemos que bien vale la pena releer y rediscutir ese momento fugaz del marxismo latinoamericano, ubicado en el cruce de los años setenta y ochenta. Pues sostenemos que las reflexiones allí desplegadas acerca de la relación entre Estado y dependencia en América Latina, pueden brindarnos interesantes claves de intelección para comprender más acabadamente algunos enigmas trascendentes de nuestro presente.

\section{Referencias bibliográficas}

Cueva, Agustín (1979): "Problemas y perspectivas de la teoría de la dependencia", en Teoría social y procesos políticos en América Latina. México, Edicol.

(1980): “América Latina en el último quinquenio: 1976-1980", en Revista Araucaria de Chile, Madrid, $\mathrm{N}^{\circ} 11$, pp. 7-18.

(1981): "El Estado latinoamericano en la crisis del capitalismo", en Revista Investigación económica, México, Vol. 40, N¹57, julio-septiembre, pp. 257-271.

(1988): "El análisis 'postmarxista' del estado latinoamericano", en Ideología y sociedad en América Latina. Montevideo, Ediciones de la Banda Oriental. 
(2009): El desarrollo del capitalismo en América Latina. México, Siglo XXI.

Kaplan, Marcos (1976): Problemas del desarrollo y de la integración en América Latina. Caracas, Monte Ávila Editores.

(1980): Sociedad, política y planificación en América Latina. México, UNAM. (1981): Aspectos del Estado en América Latina. México, UNAM.

Lechner, Norbert (2000): "Presentación", en Lechner, Norbert (Comp.), Estado y política en América Latina. México, Siglo XXI.

Chile, LOM.

(2006a): "Los patios interiores de la democracia", en Obras escogidas 1. Santiago de

Chile, LOM. (2006b): "La crisis del Estado en América Latina", en Obras escogidas 1. Santiago de

Zavaleta Mercado, René (1990a): “El Estado en América Latina”, en El Estado en América Latina. La Paz, Los Amigos del Libro.

(1990b): "Problemas de la determinación dependiente y la forma primordial", en $E l$ Estado en América Latina. La Paz, Los Amigos del Libro. (2008): Lo nacional-popular en Bolivia. La Paz, Plural. 